\title{
Effectiveness of Training and Development in the Indian Industries
}

\author{
S. Vijayasamundeeswari \\ MBA. MPHIL. PGD.HRM., Ph.D Scholar in Business Administration Manonmaniam Sundaranar University, \\ Tirunelveli.
}

\begin{abstract}
The enormous production needs of the World War I and II created a heavy influx of new workers with little or no industrial education or skills to the workplace, thereby necessitating massive training efforts that were at once fast and effective. In particular, the heavy demand for shipping construction during world war I resulted in tenfold increase in workers trained on-site instructors who were supervisor using simple force step method: show, tell, do, check. During the World War II, large numbers of trained industrial workers left their Jobs to enter the armed forces, severely limiting the organisational support normally provided by co workers in train their replacements. Heavy demands were placed on foremen and supervisors, and training within industry (TWI) service was formed to trained supervisors as the instructors. Job instruction training (JIT) was employed to train defence _ plant supervisors in instructing new employees in necessary job skills as quickly as possible. Other programs included job relations training (GRT), job methods training (GMT), and job safety training (GST). During this time, the American Society for Training and Development (ASTD) was formed. By the end of World War II most companies and organisations realized the importance of training and development as a fundamental organisational tool.
\end{abstract}

\section{Introduction}

The early $20^{\text {th }}$ century witnessed the emergence of training and development as a profession, resulting in the creation of training associations and societies, the advent of the assembly line requiring greater specificity in training, and the dramatic training requirements of the world wars important groups forming during this period include the American Management Association in 1923 (which began as the National Association of Corporation schools in 1913), and the National Management Association in 1956(which began as the National Association of Foremen in 1925). At the same time, Henry Ford (1863-1947) introduced the assembly line at his Highland Park, Michigan, plant. Because, the assembly line created an even greater division of labour, along with an unprecedented need for precision and teamwork, job tasks and assignments required more highly specific and focused training than ever before.

The enormous production needs of the World War I and II created a heavy influx of new workers with little or no industrial education or skills to the workplace, thereby necessitating massive training efforts that were at once fast and effective. In particular, the heavy demand for shipping construction during world war I resulted in tenfold increase in workers trained on-site instructors who were supervisor using simple force step method: show, tell, do, check. During the World War II, large numbers of trained industrial workers left their Jobs to enter the armed forces, severely limiting the organisational support normally provided by co workers in train their replacements. Heavy demands were placed on foremen and supervisors, and training within industry (TWI) service was formed to trained supervisors as the instructors. Job instruction training (JIT) was employed to train defence _ plant supervisors in instructing new employees in necessary job skills as quickly as possible. Other programs included job relations training (GRT), job methods training (GMT), and job safety training (GST). During this time, the American Society for Training and Development (ASTD) was formed. By the end of World War II most companies and organisations realized the importance of training and development as a fundamental organisational tool.

Hence, the researcher has taken the importance and effectiveness of training and development programmes and selected Brakes India Ltd, Chennai, Tamil Nadu, India as her area of study.

\section{Review Of Literature}

This part briefly reviews the study of different aspects of evaluation of effectiveness of training and development connected either directly or indirectly with the present study. The review of literature was highly useful to design the present study as it indicated the research gap in the study of training programmes of Brakes India Limited, Padi, Chennai. The study of training programmes, policies and practices has attracted the attention of many researchers and research organizations in western countries, particularly the United States of America. Their experiences may be of relevance and significance to us. 
K.K.Metha (1970) in his paper shares with the readers some of the problems, which make training effective. He stated that, "it is an essential investment in human resources which unlike other assets appreciates in value". He also revealed that "Training is a slow process and cannot measure its impact because of its non-tangible nature" B. Janakiraman (1994-1996) a research was conducted a research over a period of two years. His research aimed at evaluating the effectiveness of training in different circumstances involving 300 persons, 103 officers-managers of commercial banks and 89 faculties of training college

\section{Significance Of The Study}

Training and development programmes, as was pointed out earlier, help remove performance deficiencies in employees. This is particularly true when - (i) the deficiency is caused by a lack of ability rather than a lack of motivation to perform, (ii) individuals involved have the aptitude and motivation need to learn to do job better, and (iii) supervisors and peers are supportive of the desired behaviour. There is greater stability, flexibility and capacity for growth in an organisation. Training contributes to employee's stability in at least two ways. Employees become efficient after undergoing training. Efficient employees contribute to the growth of the organisation. Growth renders stability to the workforce. Further, trained employees tend to stay with the organisation. Training makes the employees versatile in operations. Growth indicates prosperity, which is reflected in increased profits from year to year.

Hence, the present research "A study on evaluation of training programmes at Brakes India limited, Padi, Chennai" has been undergone by the researcher to highlight the importance of training programmes and evaluate the effectiveness of such training programmes of Brakes India Limited, Padi, Chennai.

\section{Objectives Of The Study}

The objectives of the study are formatted to know and understand the effectiveness of the training programmes.

1. To measure the effectiveness of the training programmes.

2. To study the attitude of the employees towards impact and methods of training programmes.

3. To suggest improvements for the effective training programmes for the Brakes India Ltd., Padi, Chennai.

\section{Research Design}

This section describes the strategies or procedures that were used in data collection and analysis in order to come up with answers to the problems. This study was intended to investigate the effectiveness of training programmes in Brakes India Ltd., Padi, Chennai and to suggest concrete and effective practical evaluation strategies. Descriptive as well as analytical research design was used for the research. An exploratory survey was conducted using well-structured questionnaires.

\section{Sampling Technique}

The present study is based on both primary and secondary data. The primary data were collected from different category of employees from 14 departments such as ER \& D, Actuation, Press shop, SDI, Hose \& Rubber, Process shop, MSE \&NP, Wichitra Auto, Drum Brake, Wheel Cylinder, Freings Engineering, Aztec Auto, Task Pressings, and Rolltec Engineering, Avadi out of 41 departments, which came to 30 percent. The total number of employees working in Brakes India Ltd., Padi, Chennai as on 31.7. 2011 was 2370. Since only 14 departments were taken for the study, 500 employees were chosen as the sample for the study, which accounted to 30 percent again by using random sampling technique.

\section{Data Collection}

Human resource is the essence of development and the development largely lies with the quality of human resources. Quality of human resource depends on so many factors and training is one among the vital factors. Therefore, the researcher has made an attempt to study the performance evaluation of training and development in Brakes India Ltd., Padi, Chennai.

The present study is based on both primary and secondary data. The primary data were collected from the employees of the departments such as ER \& D, Actuation, Press shop, SDI, Hose \& Rubber, Process shop, MSE \& NP, Wichitra Auto, Drum Brake, Wheel cylinder, Freins Engg., Aztec Auto, Task Pressings and Rolltec Engg.

The primary data have been collected from the workers and supervisors, working in Brakes India Ltd. In order to collect the primary data from cross section of employees, questionnaire, containing 20 well thought out questions were issued to 520 respondents, selected on the basis of convenient sampling technique. The questionnaire is given as Appendix-I. In addition to the primary data, secondary data have been collected from published records and reports of Brakes India Ltd., Padi, Chennai, various journals, websites and books and 
Records of Madras Institution of developmental studies, Adyar, Chennai and various other libraries situated in Chennai.

Prior to the administration of the questionnaire, a pilot study was also conducted. Based on the pilot study, some questions were dropped and some questions were modified.

\section{Trainings' Effects Ripple throughout The Organization}

The training empowers employees and adds value to the organization as a whole. "It eases the burden on management when employees can alleviate situations immediately before they boil over, "From a guest complaint to a problem with a room - whatever the situation is, when employees can resolve issues, it reduces stress for everyone."

Increased employee efficacy and decreased workplace stress, results in a bonus: "It leads to satisfaction of the customer."

The correlation of employee training to employee retention is nothing to sneeze at; some studies have attributed a retention increase by as much as 70 percent to employee training. They can have a huge impact on the bottom line, especially when an organization consider the resources that go into establishing a new hire into its organization. And retention isn't the only benefit of employee training as it relates to smooth operations and financial concerns. Training increases employee efficiency and productivity (some say up to 230 per cent). It also keeps employees up-to-date with new technology and current best practices, resulting in superior job performance. From enhanced performance and increased job satisfaction, to strengthened problem-solving skills and alleviated stress, and ultimately to customer satisfaction - it's almost impossible to count the numerous ways that employee training benefits the entire organization.

\section{Analysis And Interpretation}

The researcher has discussed about the effectiveness and impact of training and development and also presented the analysis and interpretation in detail.

TABLE - 1

Showing Mean, S.D., F-value of respondents' opinion about the Effectiveness of training programs on the basis of their age

\begin{tabular}{|c|c|c|c|c|c|}
\hline Age & $\mathrm{N}$ & Mean & $\mathrm{SD}$ & F-value & LS \\
\hline $20-30$ & 220 & 53.42 & 4.24 & \multirow{4}{*}{4.22} & \multirow{4}{*}{$\begin{array}{l}0.01 \\
(\mathrm{P}<0.01)\end{array}$} \\
\hline $31-40$ & 124 & 57.42 & 6.41 & & \\
\hline $41-50$ & 94 & 51.42 & 6.72 & & \\
\hline 51 and above & 82 & 55.32 & 7.14 & & \\
\hline Total & 520 & 56.33 & 9.72 & & \\
\hline
\end{tabular}

Ha: There is a significant difference in respondents' opinion about the Effectiveness of training programs on the basis of their age.

Table reveals the Mean and SD of respondents' opinion about the Effectiveness of training programs on the basis of their age. Result proves, middle age group respondents are highly satisfied about the effectiveness of training programs than the other age groups. This difference is confirmed by the calculated Fvalue (4.22), which is significant at 0.01 level. Hence, the given hypothesis is accepted.

TABLE - 2

Showing the chi-square test for positive change after training on the basis of educational level

\begin{tabular}{|l|l|l|l|}
\hline Educational level & Yes & No & Total \\
\hline Secondary & $203(39.04 \%)$ & $11(2.12 \%)$ & $214(41.15 \%)$ \\
\hline Graduate & $119(22.88 \%)$ & $10(1.92 \%)$ & $129(24.81 \%)$ \\
\hline Post-graduate & $85(16.35 \%)$ & $12(2.31 \%)$ & $97(18.65 \%)$ \\
\hline Other specify & $71(13.65 \%)$ & $9(1.73 \%)$ & $80(15.38 \%)$ \\
\hline Total & $478(91.92 \%)$ & $42(8.08 \%)$ & $520(100.0 \%)$ \\
\hline
\end{tabular}

\begin{tabular}{|l|l|l|}
\hline Calculated chi-square value & Degrees of freedom & Level of Significance \\
\hline 5.998 & 3 & $0.1117(\mathrm{P}>0.01)$ \\
& Not Significant \\
\hline
\end{tabular}

$\mathrm{H}_{0}$ : There is no relationship between the positive change after training and their educational qualification.

The above table reveals that, the majority (91.92\%) of the respondents have opined that, there was a positive change among them after attending various training programs in the company and outside the company. Among them, the respondents with secondary level educational qualification were the majority with 39.04 per cent, 22.88 per cent were the graduates, 16.35 per cent were the post graduates and 13.65 per cent of the 
respondents belonged to the other group of educational qualification. Only 8.08 per cent of the respondents have opined that there were not any significant changes occurred after attending the training programs.

It is evident from the table that, the calculated Chi-square value is not significant at 0.01 level. Hence, the stated hypothesis is accepted. So, it is concluded that, there is no association between the positive change after the training programs and their educational qualification.

TABLE-3

Showing the chi-square test for enrich the job knowledge on the basis of educational level

\begin{tabular}{|l|l|l|l|}
\hline Educational level & Yes & No & Total \\
\hline Secondary & $188(36.15 \%)$ & $26(5.00 \%)$ & $214(41.15 \%)$ \\
\hline Graduate & $119(22.88 \%)$ & $10(1.92 \%)$ & $129(24.81 \%)$ \\
\hline Post-graduate & $67(12.88 \%)$ & $30(5.77 \%)$ & $97(18.65 \%)$ \\
\hline Others & $70(13.46 \%)$ & $10(1.92 \%)$ & $80(15.38 \%)$ \\
\hline Total & $444(85.38 \%)$ & $76(14.62 \%)$ & $520(100.0 \%)$ \\
\hline
\end{tabular}

\begin{tabular}{|l|l|l|}
\hline Calculated chi-square value & Degrees of freedom & Level of Significance \\
\hline 26.88 & 3 & $0.001(\mathrm{P}<0.01)$ Significant \\
\hline
\end{tabular}

$\mathrm{H}_{0}$ : There is no relationship between the enrichment of job knowledge and their educational qualification.

As far as the above table is concerned, 85.38 per cent of the respondents have accepted that, the training programs certainly enrich their job knowledge. Among them, 36.15 per cent of them had secondary level of educational qualification, 22.88 per cent of them were graduates, 12.88 per cent of the respondents were post graduates and 13.46 per cent of them belonged to the others category. 14.62 per cent of the respondents have rejected the statement that, the training programs enrich their job knowledge.

It is evident from the table that, the calculated Chi-square value is significant at 0.01 level. Hence, the stated hypothesis is rejected. So, it is concluded that, there is an association between the enrichment of the job knowledge and their educational qualification.

TABLE - 4

Showing the Stepwise Regression Analysis for the Effectiveness of Training Programs

\begin{tabular}{|l|l|l|l|l|l|}
\hline Sl.No & Step/Source & Cumulative $\mathbf{R}^{\mathbf{2}}$ & $\Delta \mathbf{R}^{\mathbf{2}}$ & Step t & $\mathbf{P}$ \\
\hline 1. & Educational level & 0.042 & $0.052^{*}$ & 3.194 & 0.01 \\
\hline 2. & Length of service & 0.055 & $0.049^{*}$ & 2.423 & 0.01 \\
\hline 3. & $\begin{array}{l}\text { Number of training programme } \\
\text { attended }\end{array}$ & 0.069 & $0.058^{*}$ & 2.314 & 0.01 \\
\hline
\end{tabular}

$* \mathrm{P}<0.01$

Constant value $=17.424$

Three variables namely, educational level, length of service and number of training programs attended have significantly contributed for predicting the effectiveness of training programs. The variable educational level predictive value of effectiveness of training programs seems to be 0.042 , when paired with the variable, length of service is 0.055 and with number of training programs attended is 0.069 . The predictive value of these variables separately is 0.01 .

Training is an educational process. People can learn new information, re-learn and reinforce existing knowledge and skills, and most importantly have time to think and consider what new options can help them improve their effectiveness at work. Effective trainings convey relevant and useful information that inform participants and develop skills and behaviours that can be transferred back to the workplace.

\section{Suggestions}

The goal of training is to create an impact that lasts beyond the end time of the training itself. The focus is on creating specific action steps and commitments that focus people's attention on incorporating their new skills and ideas back at work.

- The employees must be given enough training materials for their needs. So that, they could refer it, whenever they require it.

- Since the employees are continuously involved in the production, they can be given training programs related to their personality or how to balance their work life with personal life.

- After taking up training programs, employees can be given opportunity to implement the learned changes necessary in their work environment. 
- Company has to make the employees understand that, the main reason for the conduction of training programs is not only for one or two factors, but also for the overall efficiencyof the company.

- The organization needs consistently to apply strategies for the evaluation of training and development initiatives. Also, these strategies must be reflected in the company's training policy. In view of these strategies, it is important that, the organization becomes a learning one, in which training and development become critical components of efficiency and effectiveness and that a performance management system be incorporated into the training strategy.

\section{Conclusion}

It can be concluded that for training and development to be effective, the organisation should become a learning organisation, whereby learning is encouraged by all stakeholders from individual employees to management. It is therefore imperative, for management to implement and proper learning processes in the organisation. The effectiveness of the training programs lies in the company's training process. On the whole, the employees are satisfied with the present training processes of the company, which is analysed through various statistical tools. The company is suggested to follow the recommendations, which is given by the researcher after a deep study. Thus, the employees will be to obtain considerable satisfaction in their training programs. 